\title{
The new era of large paraboloid antennas: the life of Prof. Dr. Otto Hachenberg
}

\author{
R. Wielebinski \\ Max-Planck-Institut für Radioastronomie, Auf dem Hügel 69, 53121, Bonn, Germany
}

\begin{abstract}
Seldom does a scientist get an opportunity in his lifetime to build an instrument that remains unchallenged as the world's no. 1 for 30 years. The Effelsberg 100$\mathrm{m}$ radio telescope, constructed under the direction of Prof. Dr. Otto Hachenberg, was the world's largest fully steerable paraboloid antenna since its inauguration in 1971. The radio telescope in a valley in the Eifel mountains near Bonn was constructed with a remarkably precise surface and excellent pointing characteristics. Only in 2001 the $100-\mathrm{m} \times 110-\mathrm{m}$ Green Bank Telescope became operational and marginally surpassed Effelsberg's performance. The Effelsberg telescope is still fully operational in 2002 and looking forward to an exciting future. It is a memorial to the ingenuity of a person who influenced the development of German radio astronomy.
\end{abstract}

\section{Introduction}

The pioneering measurements of Karl Jansky and Grote Reber made in the USA in the 1930's opened up a new (radio) window on the Universe. The development of radio astronomy was shaped by World War II. The results of Jansky's experiments were known in Germany and led to early attempts to check them (e.g. Fränz, 1942). Also reports about radar interference due to solar emission were made by German stations, but disappeared in top secret military reports. These reports were taken over by the Allies and remained confidential. As a result in papers describing the history of radio astronomy (e.g. see Sullivan, 1984) the German development was commented to be only the construction of the 7.5-m Würzburg (radar) antennas. These antennas were used for many years after World War II in pioneering radio observations in Holland, England and Sweden. No Würzburg antenna was given to the German astronomers to conduct radio astronomy experiments. In fact radio research was forbidden

Correspondence to: Gabriele Breuer

(p647gbr@mpifr-bonn.mpg.de) in Germany until 1950 so that the contact to the developments in other countries was lost.

\section{The early years}

Otto Hachenberg was born on 25 June 1911 in Anhausen near Koblenz. He studied Physics and Astronomy at the Berlin University. He worked at the Berlin-Babelsberg Observatory with P. Guthnik and W. Grotrian. His early publications deal with the photometry of stellar clusters using electronic methods. He was interested in the techniques of electronic light detection and spent some time developing the early spectrographs with photodetectors. He was awarded his Doctoral title in 1938.

The interest of Otto Hachenberg in technical aspects of astronomy led him to move to a laboratory of the Telefunken company in Berlin in 1939, that was pioneering photomultipliers that led to the commercial development of television. The World War II caught Otto Hachenberg in this technical laboratory, involved a crucial wartime industry. One of the tasks that he was given was to recover radar sets from airplanes that were shot down and reconstruct them. I have witnessed an interesting conversation in 1970 in Bonn between Dr. E.G. (Taffy) Bowen (then director of CSIRO Radiophysics division in Australia) who was installing the radar sets in the Allied bombers and Otto Hachenberg who recovered the radar sets. The two gentlemen sketched on a serviette the layout of some radar set that Otto Hachenberg recovered intact from a plane that was forced to land in Holland and whose destroy mechanism did not work. Another amazing conversation took place during a visit of Sir Bernard Lovell in 1977 to the Effelsberg radio telescope. Professor Hachenberg recalled that magnetrons were used in Telefunken laboratories for signal generators but not for radar transmitters. Sir Bernard Lovell believed that only the British had developed magnetrons that were so important in high frequency radar. 
Professor Hachenberg was asked to take charge of the Heinrich-Hertz-Institut für Schwingungsforschung in BerlinAdlershof in 1951. Restrictions of doing radio research in Germany were lifted in 1950. This was his opportunity to start basic research of solar radio emission, the Earth's magnetosphere and develop techniques of radio astronomy. In particular, the effective use of a radiometer during a solar eclipse in 1954 gave support to this direction of research. The Academy in Berlin (East), later the Academy of the German Democratic Republic, gave green light for a construction of a 'giant' transit radio telescope with 32-m diameter for the Heinrich-Hertz Institute. This telescope was an important step in the design of further instruments with precise surfaces, a basis for high-frequency radio observations. The space frame of the 32-m telescope could not be designed analytically. The computer power needed was also not available at the time. The space frame was made in the Junkers factory in Dessau, where a test rig was organized. The telescope frame was loaded with concrete weights on this test rig giving important information about the deflection characteristics of such constructions. One of the most important conclusions was the observation that a symmetrical structure deflects in a similar way in all the sections. This implied that once one section was analyzed the deflection behavior of the whole structure could be predicted. Professor Hachenberg did not reap the benefit of 'his' telescope: the construction of the Berlin Wall in 1961 left him isolated from his institute since he was living in West Berlin and access was denied in spite of representations by the Academy of the GDR.

The next step in the career of Professor Hachenberg was to move to Bonn University in 1962 where a 25 -m radio telescope was operational on the Stockert mountain. He was appointed to the chair of Radio Astronomy and to the Directorship of the Stockert Observatory. Under the direction of Professor Hachenberg electronic laboratories were supported to construct the most modern receivers for observations. The Stockert telescope was equipped with some of the earliest cryogenically cooled parametric amplifiers as a result of Professor Hachenberg's drive. Publications about $\mathrm{HI}$ emission from the Galaxy and continuum maps at high frequencies were a result of these innovations. At the same time a $10-\mathrm{m}$ telescope was constructed for $\mathrm{mm}$-wave solar research at Stockert. Professor Hachenberg supported also the development of infrared technology, seeing clearly that this would be the next important direction of development in astronomy. In spite of his interests in many directions he was planning a real 'giant' radio telescope.

\section{The 100-m radio telescope}

The opportunity for the 'giant' radio telescope came in the 1960's when a lot of ambitious projects could be funded. At this time also computer programs became more powerful so that the 'orange-slice' of a space frame could be studied numerically and in combination with the 32-m telescope studies made in Dessau could lead to a real design. An application for funds for a giant radio telescope was made to the Volkswagenstiftung in May 1964 by Prof. Friedrich Becker, Prof. Wolfgang Priester and Prof. Otto Hachenberg, all professors at the Bonn University. Study funds were granted in October 1964 that led to a world trip by Prof. Hachenberg and Prof. Priester to visit large radio telescopes then in operation. It was during that journey in 1965 that the author's first personal contact with Otto Hachenberg was made: I was asked to look after the visitors during a weekend in Sydney, show them the Fleurs field station of the University of Sydney, before they continued on to the Parkes radio telescope. The trip took Profs. Hachenberg and Priester across the Pacific to the large USA telescopes, namely the Owens Valley Observatory, the DSN facility in California and to the National Radio Astronomy Observatory in Green Bank. In Green Bank Prof. Hachenberg met Professor Sebastian von Hoerner who was also planning a large telescope. In fact a political situation arose with two proposals being made to the Volkswagenstiftung at the same time. In a Salomonic decision each of the proposals was granted half the money. Prof. Hachenberg placed contracts for design studies with the firms of MAN (who had built the Parkes telescope) and with Krupp. At first the proposed telescope diameter was fixed at $80-\mathrm{m}$ but the 100-m option was high in Prof. Hachenberg's mind. In the design discussions Prof. Hachenberg was very active in bringing in his ideas going back to the studies that he made in Dessau on the 32-m telescope space frame. The FRAN program was by then available and the computations indicated that a self-compensating elastic structure could work. Rather than making the space-frame structure more rigid elastic deformations were allowed but the design was made in such a way that a paraboloid would deflect into another paraboloid needing only a change of the focus. This was a revolutionary idea! This numerical solution was almost at the same time demonstrated to be solvable analytically by Prof. Sebastian von Hoerner and is now known as HOMOLOGY.

The operation of a large radio telescope needs an appropriate institute with strong technical (hardware and software) support. This large institute was not so easy to organize within a typical university department. The Max-PlanckGesellschaft, that was able to fund larger institutes, had decided to fund a new MPI für Radioastronomie with Professor von Hoerner and Professor Hachenberg as Directors. The suggested place for the institute was Tübingen. This led to considerable political activity since the established Radio Astronomy Observatory was in the Bonn University. Also the local Government, especially the secretary of state for research in Nordrhein-Westfalen, Leo Brandt, was adamant that the new facility should remain in Nordrhein-Westfalen. As a result of these lengthy discussions, Prof. von Hoerner decided to stay in the USA and the Volkswagenstiftung gave the full sum to the Bonn project. The MPG senate decided on 23 June 1965 to site the new MPIfR in Bonn. Professor Otto Hachenberg became the founding director.

The decision to build a $100-\mathrm{m}$ radio telescope fell in 1966. The firms of MAN and Krupp were asked to combine forces in the construction by forming an "Arbeitsge- 
meinschaft" (ARGE), a combined project company. Many of the contracts were being placed and the contract for the steering of the telescope was given to the firm of AEGTelefunken. It was to be from the beginning to be a fully computer-controlled telescope. In a way the innovations in the Effelsberg telescope were unprecedented. Many new methods were being incorporated in the design at the same time. The telescope was to have a Gregorian geometry to allow the use of both the prime focus and the secondary focus. For papers giving some of the details of the planning the reader is referred to: Hachenberg (1968), Schönbach (1968), Hachenberg (1970), Wielebinski (1970) and Hachenberg et al. (1973). The site selection was going on since the MPIfR was founded. Many sites were considered and based on the Stockert experience the goal was to find a deep valley opening to the south. This was found near the village of Effelsberg which is part of the town of Bad Münstereifel. The site was purchased by the Goverment of Nordrhein-Westfalen and it is exactly on the boarder to Rheinland-Pfalz. In fact the creek that is the boarder between the two Länder (local States) had to be moved several meters, so that Nordrhein-Westfalen was enlarged by some 200 of square meters in this process.

The telescope construction started in 1968 with the pouring of a ring foundation that was to carry a 64-m azimuth railtrack of considerable accuracy. Piles had to be sunk to the rock underground to ensure stability. Since the design was predicted to give $6 \mathrm{GHz}$ operation and there was justified hope to use the telescope at even $23 \mathrm{GHz}$, the specification for the track was very stringent. The construction of the telescope proceeded in 1969 with the A-frame towers being assembled on the railtrack and the 'orange-slice' space frame being welded on ground nearby. A 100-m crane started to assemble the space frame so that by 1970 the main construction was complete. In the same year the panels were placed in the telescope back-up structure. Three types of panels were used. The inner 60-m surface was filled with aluminum honeycomb panels of considerable accuracy. The rings between $60-\mathrm{m}$ and $80-\mathrm{m}$ diameter were filled with aluminum frame panels. The final three outer rings of panels had a steel frame and glued mesh surface. A transfer ring of perforated aluminum surface was placed between the mesh panels and solid surface panels to reduce the wind load. In 1971 the first drive tests were made. On 23 April 1971 the 'first light' observation was made at $11 \mathrm{~cm}$ wavelength. In the earliest phase of the tests a $408 \mathrm{MHz}$ receiver was placed in the telescope and was used for astronomical observations in the intervals when welders were not at work. The official inauguration of the telescope took place on 12 May 1971.

The early tests showed that there were still some problems with the telescope drive system. Oscillations were noticed and tracked to the double elevation drive. A modification of this drive solved the oscillation problem. The astronomical drive program, designed by Stumpff et al. (1972) using a Ferranti 500 computer, was optimized. A test phase was needed to determine the focus correction to account for the 'homological' design. These corrections determined by observing radio sources came close to the predicted values from

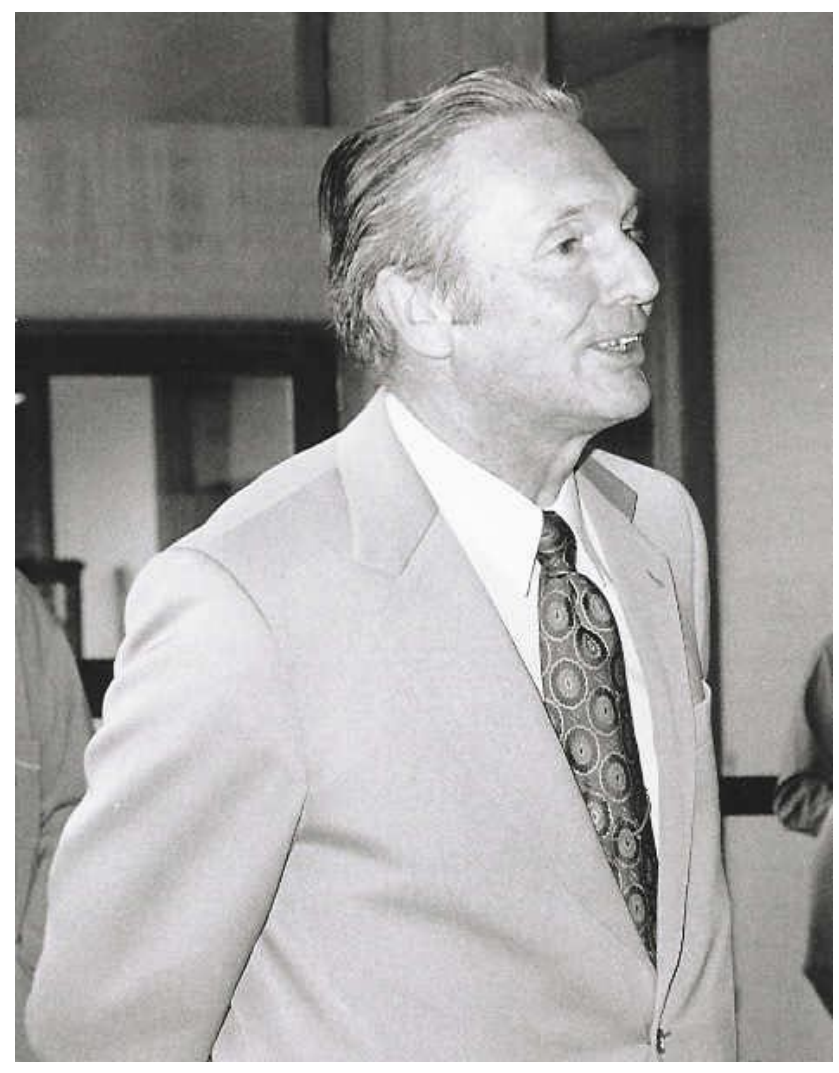

Fig. 1. Professor Otto Hachenberg at the inauguration of the new MPIfR building in 1973.

the computations in the design. This was a heartening result indicating that the gamble of the light and elastic design did work! Finally the first astronomical observations could be started in June 1972. At first only a $2.7 \mathrm{GHz}$ receiver was available. In the second half of 1972 a $10.6 \mathrm{GHz}$ receiver was put in the telescope confirming the predictions of design. The first publication, describing pulsar observations at $10.6 \mathrm{GHz}$, was published by Wielebinski et al. (1972). The surface accuracy was $\sim 1 \mathrm{~mm}$ r.m.s. and the pointing could be held at $\sim 10^{\prime \prime}$ r.m.s. This was a breakthrough in telescope design! The following years saw the additions of yet new receivers at higher frequencies. Before his retirement in 1979 Prof. Hachenberg was able to map the sun with the 100-m telescope at $17 \mathrm{GHz}$ (Fürst et al., 1974). Also before his retirement Prof. Hachenberg was actively involved in the foundation of IRAM, the French-German-Spanish Institute for mm-wavelength radio astronomy in Grenoble and in the design of the 30-m mm-wavelength telescope at Pico Veleta near Granada.

\section{Summary}

The 100-m radio telescope has been successively improved over the past 30 years and can now be used even at $86 \mathrm{GHz}$, $3 \mathrm{~mm}$ wavelength. The surface of the Effelsberg telescope has been improved to $\sim 0.4 \mathrm{~mm}$ r.m.s. by replacing the outer 
panels and by holographic surface setting. The pointing of Effelsberg is now $\sim 3^{\prime \prime}$ r.m.s. as a result of new (stiffer) gears and optimization of the drive. The 100-m telescope and the astronomers of the MPIfR have produced more than 2000 publications with this instrument up till now. The Effelsberg radio telescope is used in a world wide net of instruments in intercontinental very long baseline interferometry. It is used in every type of radio astronomical research: continuum, polarimetry, spectroscopy, pulsars and VLBI. The recent completion in the USA of the $100-\mathrm{m} \times 110-\mathrm{m}$ Green Bank Telescope (GBT) can lead to several interesting comparisons. The GBT took ten years to complete. The GBT weighs three times more than Effelsberg because it uses a stiff space frame and actuator mounted panels. The GBT has a slight advantage in performance at present. With the addition of a new subreflector, with actuators, a very similar performance can be achieved in Effelsberg as is now being implemented in the GBT.

Professor Dr. Otto Hachenberg died on 24 March 2001. The Effelsberg radio telescope is a great monument to his ingenuity.
Acknowledgements. I like to thank Dr. B. Grahl who has given me much of the information about the early days of German radio astronomy.

\section{References}

Fränz, K.: Hochfrequenz und Elektroakustik 59, 143, 1942.

Fürst, E., Hachenberg, O., and Hirth, W.: A \& A, 36, 123, 1974.

Hachenberg, O.: Beiträge zur Radioastronomie 1, 31, 1968.

Hachenberg, O.: Sky \& Telescope 40, 1, 1970.

Hachenberg, O., Grahl, B., and Wielebinski, R.: Proc I.E.E.E., 61, 1288, 1973.

Schönbach, W.: Der Stahlbau, Heft 12, p. 1, Verlag Ernst \& Sohn, 1968.

Sullivan, W. T. III: The Early Years of Radio Astronomy, Cambridge University Press, 1984.

Stumpff, P., Girnstein, W., Voss, W., and Schraml, J.: Mitt. Astr. Ges. 31, 101, 1972.

Wielebinski, R.: Nature, 228, 507, 1970.

Wielebinski, R., Sieber, W., Graham, D., et al.: Nature 240, 131, 1972. 